\title{
Economic value of using partially hydrolysed infant formula for risk reduction of atopic dermatitis in high-risk, not exclusively breastfed infants in Singapore
}

\author{
Marc F Botteman $^{1}$, MSc, MA, Abhijeet J Bhanegaonkar ${ }^{1}$, PhD, MPH, Erica G Horodniceanu ${ }^{1}$, Bs, Xiang $\underline{J i}^{1}$, MA, \\ Bee Wah $\underline{\text { Lee }}^{2}$, MMed, MD, Lynette P $\underline{\text { Shek }^{2}}$, MBBS, FRCPCH, Hugo PS Van Bever ${ }^{2}$, MD, PhD, Patrick Detzel ${ }^{3}$, PhD
}

\begin{abstract}
INTRODUCTION Previous trials have demonstrated reductions in atopic dermatitis (AD) incidence when healthy, high-risk, non-exclusively breastfed infants were fed until four months of age with $100 \%$ whey-based partially hydrolysed formula (PHF-W) versus standard cow's milk formula (CMF). We assessed the cost-effectiveness of this intervention in Singapore. METHODS Modelling techniques were used to simulate, from birth to Month 30, the incidence and clinical/economic burden of $A D$ in high-risk, non-exclusively breastfed infants fed with PHF-W or CMF for up to four months. Epidemiologic and clinical data were from a local comparative trial. Expert opinion informed AD treatment patterns and outcomes. Outcomes included reduction in AD risk, time spent with AD, days without AD flare, quality-adjusted life years (QALYs) and direct/indirect costs. Multivariate probabilistic sensitivity analysis was used to assess model parameter uncertainty. RESULTS Over 30 months, with the use of PHF-W instead of CMF, the proportion of children who developed AD and the time spent with $A D$ decreased by $16.0 \%$ (28.3\% vs. $44.3 \%$ ) and 6.4 months, respectively, while time without AD flare and QALYs increased by 14.9 days and 0.021 QALYs per patient, respectively. Estimated AD-related discounted costs per child for PHF-W and CMF were SGD 771 and SGD 1,309, respectively (net savings: SGD 538). PHF-W was less expensive and more effective than CMF for $73 \%$, and cost less than SGD 50,000 per QALY for $87 \%$ of all multivariate simulations. CONCLUSION Early short-term nutritional intervention with PHF-W instead of CMF may reduce AD incidence and costs for healthy, high-risk, non-exclusively breastfed infants in Singapore.
\end{abstract}

Keywords: atopic dermatitis, cost-effectiveness, health economics, partially hydrolysed formula-whey, risk reduction

\section{INTRODUCTION}

Atopic dermatitis (AD) is an inflammatory skin disorder mainly affecting infants and young children. ${ }^{(1)}$ In Singapore, studies have found that approximately $8 \%-23 \%$ of children aged $6-7$ years had atopic eczema ${ }^{(2,3)}$ and approximately $10 \%-14 \%$ of preschoolers aged 4-6 years had eczema that was chronic or had a flexural distribution at the time of the study. ${ }^{(4)}$ Secular trends suggest that this prevalence may be increasing in many Asian countries. ${ }^{(5,6)}$

$A D$ is caused by a combination of immunologic, environmental and genetic factors. ${ }^{(2,7,8)} \mathrm{A}$ child's risk of developing allergies is $2-4$ times higher if one or both parents have allergies, ${ }^{\left({ }^{(8)}\right.}$ and $70 \%$ of children with $\mathrm{AD}$ in Singapore have at least one first-degree family member with atopy. ${ }^{(2)} \mathrm{AD}$ may be caused by factors such as skin barrier defects, allergic reactions, autoimmunity and microbial agent colonisation, ${ }^{(6)}$ and is characterised by a chronic component that can lead to lifelong symptoms. ${ }^{(9)}$ Thus, $\mathrm{AD}$ imposes a substantial economic and quality-of-life (QOL) burden on patients, families and societies. ${ }^{(10-13)}$

The World Health Organization and the authors of the present analysis unequivocally recommend exclusive breastfeeding through the first six months of life and, thereafter, continued breastfeeding with complementary foods up to two years of age or beyond. ${ }^{(14)}$ Breast milk is without a doubt the optimal source of nutrition for infants, providing numerous short- and long-term medical and neurodevelopmental advantages including, among others, protection against infections ${ }^{(15)}$ and possible reduction in the incidence of asthma and AD. ${ }^{(16-18)}$ However, this recommendation is not always followed in practice, and in such instances, high-risk infants fed with standard cow's milk formula (CMF) as a breast milk supplement or replacement may be exposed to a higher likelihood of developing AD. Study results from various countries indicate that one-third of children with $\mathrm{AD}$ have a cow's milk allergy/intolerance diagnosis and at least $50 \%$ of infants with cow's milk allergy/intolerance have AD. ${ }^{(19,20)}$

To reduce the allergy risk associated with cow's milk protein, non-exclusively breastfed infants may be given partially or extensively hydrolysed formulas instead of CMF. (21) Reports published by the American Academy of Pediatrics, ${ }^{(22)}$ and the European Society for Paediatric Allergology and Clinical Immunology and European Society for Paediatric Gastroenterology, Hepatology and Nutrition ${ }^{(23)}$ have considered the use of hydrolysed infant formulas as a strategy to reduce allergy risk for high-risk, formula-fed infants.

Results from studies ${ }^{(24-26)}$ and some, ${ }^{(21,27,28)}$ although not all,(29) meta-analyses show a reduction in $\mathrm{AD}$ incidence with early feeding of high-risk infants using 100\% whey-based partially hydrolysed formula (PHF-W) or extensively hydrolysed caseinbased formula (EHF-C) compared to CMF. In particular, a clinical

${ }^{1}$ Pharmerit International, Bethesda, Maryland, USA, ${ }^{2}$ Department of Paediatrics, Khoo Teck Puat-National University Children's Medical Institute, National University Hospital, Singapore, ${ }^{3}$ Nestlé Research Center, Lausanne, Switzerland

Correspondence: Mr Marc F Botteman, Partner, Pharmerit International, 4350 East West Highway, Suite 1110, Bethesda, Maryland 20814, USA. mbotteman@pharmerit.com 


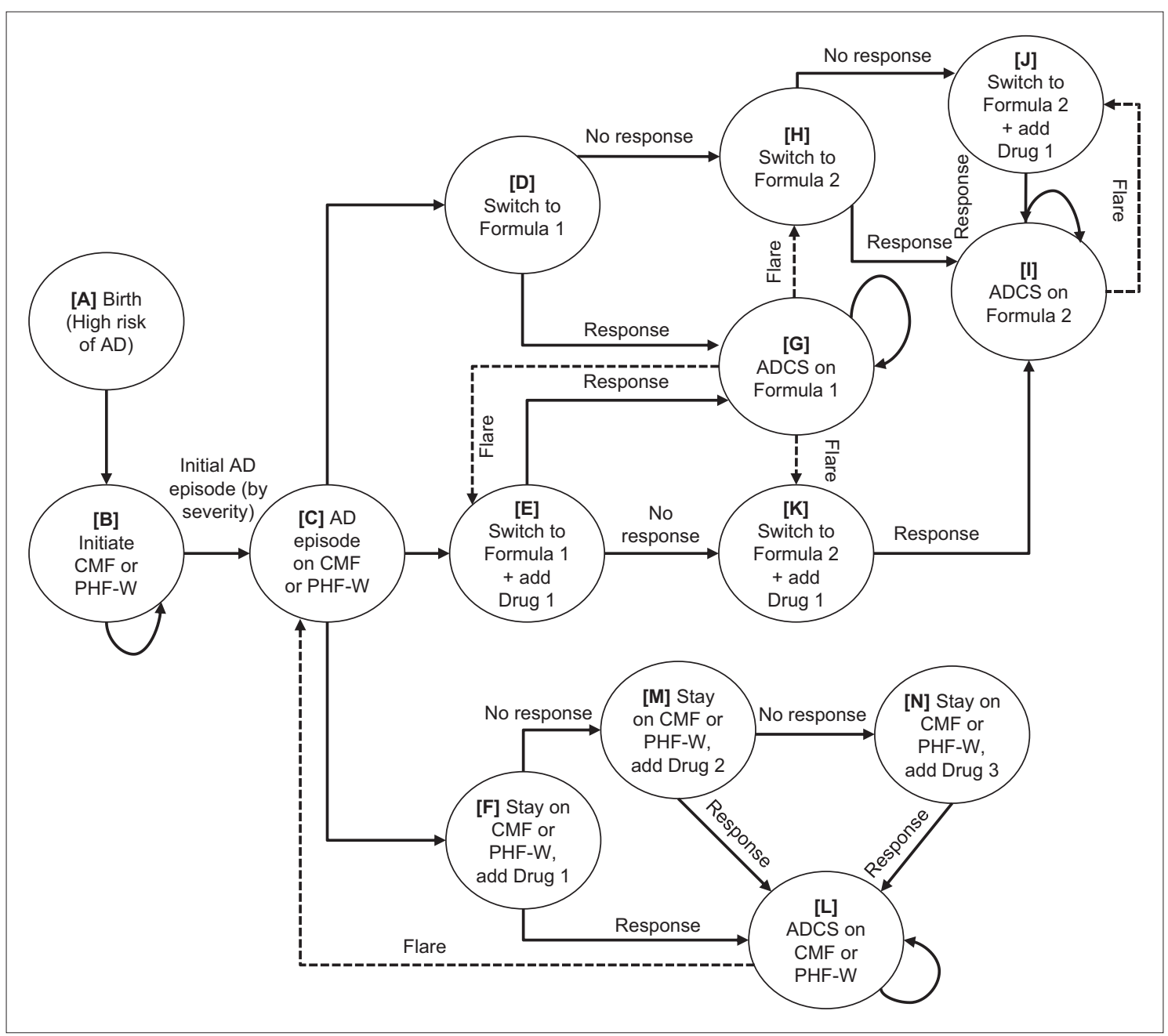

Fig. 1 Figure shows the simplified model structure. Cohorts of newborns who had not developed AD (A) entered the model at the time of initiation of a four-month course of PHF-W or CMF (B). If or when AD developed (C), three treatment approaches were considered: formula change alone (D); a combination of formula change and first-line pharmacotherapy $(E)$; or first-line pharmacotherapy alone $(F)$. In $D$, if there was a response within two weeks of formula change, the child was considered to enter an AD-controlled state (ADCS) on first-line treatment formula, i.e. Formula 1 (G), or in the case of non-response, was switched to a second-line treatment formula, i.e. Formula $2(H)$. Upon experiencing a flare, patients in ADCS (G) who were previously treated with Formula $1(D)$ transitioned to treatment with Formula $2(H)$, or had first-line pharmacotherapy (Drug 1$)$ added $(K)$. If there was a response to Formula $2(\mathrm{H})$, patients entered ADCS (I). In cases of non-response to Formula $2(\mathrm{H})$ or a flare in ADCS (I), Drug 1 would be added (J). For simplicity, the model assumed response was achieved at this point and the patient entered ADCS on Formula 2 (I). In cases that were switched to Formula $1+$ Drug $1(E)$, pharmacotherapy would end if response occurred and the child was considered to enter ADCS on Formula 1 (G). Otherwise, the patient would switch to Formula 2 while remaining on the same pharmacotherapy (K). At this point, response would occur and the patient entered ADCS on Formula 2 (I). If a response was experienced while on Drug 1 along with the original treatment formula (F), the child was considered to enter ADCS on the original treatment formula (L). Otherwise, the patient remained on the original treatment formula and was switched to second- and thirdline pharmacotherapy (Drug $2[\mathrm{M}]$ and Drug $3[\mathrm{~N}]$ ) until response occurred, at which point the patient entered ADCS on the original treatment formula $(\mathrm{L})$. A child in ADCS on the original treatment formula after pharmacotherapy $(\mathrm{L})$ and who was experiencing a flare was assumed to have been treated by either a change in formula, pharmacotherapy or both. Solid lines indicate response or non-response following treatment. Dotted lines indicate flare following treatment. AD: atopic dermatitis; CMF: standard cow's milk formula; PHF-W: partially hydrolysed whey-based formula

trial involving 110 Singapore children with first-degree atopic family history followed from birth to 30 months of age showed that the onset of AD was delayed when they were exclusively fed with PHF-W compared to CMF. ${ }^{(30)}$ The cumulative eczema incidence in the PHF-W group compared to the CMF group was significantly lower at three, six, 12, 18 and 24 months and lower (28.3\% vs. $43.9 \%$ ), albeit not significantly so, at the last follow-up (Month 30), suggesting that PHF-W delayed the onset of AD until Month 24 but not beyond that. ${ }^{(30)}$ Furthermore, results of economic analyses based on the German Infant Nutritional Intervention (GINI) study demonstrated that PHF-W was cost-effective compared to CMF in high-risk, non-exclusively breastfed infants. ${ }^{(31-36)}$ A majority of these analyses were conducted from a Western perspective, except for two studies conducted in the Philippines ${ }^{(36)}$ and Malaysia. ${ }^{(35)}$

The availability of clinical trial data from Singapore ${ }^{(30)}$ provides a unique opportunity to analyse the cost-effectiveness of PHF-W using local evidence. Thus, the present analysis used data from the Singapore trial by Chan et al ${ }^{(30)}$ in combination with additional sources to analyse, from a societal perspective, the economic impact of exclusive use of PHF-W compared to CMF in healthy infants at high risk of $A D$ in Singapore, as a short-term, early nutritional intervention for $\mathrm{AD}$ risk reduction.

\section{METHODS}

Markov cohort modelling techniques ${ }^{(37)}$ were used to estimate the effect of exclusive use of PHF-W instead of CMF in the first 
four months of life on AD burden over the first 30 months of life in healthy, non-exclusively breastfed, high-risk infants (i.e. those with a parent or sibling with an allergic disease history). ${ }^{(22,24)}$ The target population was assumed to be consistent with that of Chan et al. ${ }^{(30)}$ Fig. 1 graphically depicts the structure of the Markov model.

The cumulative proportion of children who developed AD over time was calculated in two-week intervals, taking into consideration age and initial formula received. Based on previous models $s^{(31,33,34,36)}$ and the opinion of three Singapore clinicians with expertise in treating paediatric patients with $A D$, the following three AD treatment approaches were considered: (a) switch formula (i.e. switch infant formula only); (b) combined (i.e. switch infant formula and add first-line pharmacotherapy); or (c) medical (i.e. add first-line pharmacotherapy only, e.g. topical and oral steroids, tacrolimus). All formula use for the treatment of AD was assumed to last until Month 12, using nutrition requirement- and age-appropriate volumes based on formula labels for PHF-W and CMF. As in Chan et al, ${ }^{(30)}$ the assigned diet was given exclusively in the first four months of life, after which the infants were allowed to have a weaning diet with no dietary restrictions, except for the type of milk formula. In the model, this was assumed to last until the end of 12 months, whereas this was allowed until the end of the trial. Infants with AD aged 12 months or less who switched to a treatment formula were assumed to receive soy formula as first-line therapy and EHF as second-line therapy. Since formula use was assumed to end beyond 12 months of age, the pharmacotherapy-only treatment approach was always used after Month 12 .

Treatment response rates, varying by severity and treatment approach/line, were assessed biweekly and represented the speed at which $\mathrm{AD}$ symptoms resolved and children transitioned to the AD-controlled state (ADCS). Children with AD responding to a treatment formula switch were assumed to remain on that formula until Month 12 or the next AD flare. Patients responding to pharmacotherapy completed their treatment course and remained on their assigned formula. Flare risk after entering ADCS was based on age and AD severity at initial presentation. The model also included mortality (based on World Bank data) ${ }^{(38)}$ to account for lost investment in PHF-W in case of premature death.

Several clinical and epidemiological inputs, including distribution of $\mathrm{AD}$ severity at initial presentation, treatment patterns, resource uses, response rates, flare rates and distribution of speciality visits by $\mathrm{AD}$ severity at initial presentation, were derived from the experience of the clinicians involved in the study (Tables I-III). The biweekly age-stratified probability of AD for PHF-W and CMF was obtained using linear interpolation between the 0-, 3-, 6-, 12-, 18-, 24- and 30-month cumulative incidence data from Chan et $\mathrm{al}^{(30)}$ (Table I). Infant formula daily intake was calculated according to Iskedjian et al. ${ }^{(31)}$ The analysis included direct, indirect, medical and non-medical costs associated with infant formula-feeding and AD treatment, which are further described herein. Resource use included the rates of physician and hospitalisation visits, diagnostics, pharmacotherapies and other costs (e.g. time loss, travel costs) associated with the management of $\mathrm{AD}$ at initial presentation and in case of nonresponse/flare (Table III). Based on expert opinion, the use of emollient was assumed to continue between flares at a rate of $63 \mathrm{~g} /$ week.

Table IV presents price assumptions for resources. Infant formula acquisition prices were derived using local data. ${ }^{(39)}$ Only the additional cost incurred as a result of feeding with an alternative infant formula above and beyond CMF cost was considered. Physician visit costs were obtained from consultant charges, as recommended by the Ministry of Health, Singapore. ${ }^{(40)}$ Laboratory and diagnostic test costs upon initial AD diagnosis were estimated based on hospital laboratory fees, as reported by physicians in Singapore. Hospitalisation costs were estimated based on general room rates derived from four Singapore hospitals (three public and one private). Medicine prices were based on local hospital pricing obtained by Nestlé field operations staff. Parent time loss while caring for a child with AD (i.e. travelling to and visiting a clinic) was estimated via expert opinion and valued using an average hourly wage of SGD 31.73 (USD 25.38), ${ }^{(41)}$ adjusted for $66.7 \%$ labour force participation. ${ }^{(42)}$ Travelling costs to/from clinics were estimated by multiplying distance travelled by average cost per mile. ${ }^{(43)}$ Conservatively, no other costs were considered.

QOL was included in the model via the use of utilities to allow the estimation of quality-adjusted life years (QALYs; Table IV). ${ }^{(44,45)}$ Children without $A D$ were assumed to experience perfect health (i.e. full utility $=1.000$ ). Any child after initial AD diagnosis was assumed to have a utility slightly less than 1.000 regardless of flare status, to recognise the mild reduction in QOL due to minimal, subclinical episodes. Death was associated with a utility of zero.

Outcome measures included: (a) proportion of patients developing AD; (b) average time between $\mathrm{AD}$ diagnosis and end of the 30-month period (i.e. the time spent with AD); and (c) the number of days without an $\mathrm{AD}$ flare. The relative economic value of PHF-W compared to CMF was evaluated using incremental cost-effectiveness ratios (ICERs), including the incremental cost per AD case avoided, AD-free day gained and QALY gained. All results were reported after applying a 3\% discount rate to all costs and effects beyond Year 1, consistent with general guidelines for health economics research and a previous local economic evaluation. ${ }^{(35,46)}$ Costs were in 2013 Singapore dollars (SGD $1.00=$ USD 0.80).

QALY gained was calculated by dividing the difference in costs between PHF-W and CMF by the differences in clinical outcome. Deterministic univariate sensitivity analyses (USA) and multivariate probabilistic sensitivity analyses (PSA) were conducted to assess the effect of model parameter uncertainty on outcomes. Specifically, deterministic uSA were conducted on individual model parameters while keeping the base-case values for other parameters unchanged. In the multivariate PSA, model outcomes were calculated 5,000 times via Monte Carlo simulation techniques, using a different value for each input parameter from appropriate theoretical or empirical distributions. The proportion of PSA simulations in which PHF-W resulted in lower costs and higher QALYs compared to CMF and the 95th percentile of cost per QALY was reported. 
Table I. Epidemiologic inputs.

\begin{tabular}{|c|c|c|c|c|}
\hline \multirow[t]{2}{*}{ Variable } & \multirow[t]{2}{*}{ Base case } & \multicolumn{2}{|c|}{ Value in uSA } & \multirow[t]{2}{*}{ PSA distribution } \\
\hline & & Low & High & \\
\hline \multicolumn{5}{|c|}{ Probability of AD with $\mathrm{CMF}^{(30)}(\%)$} \\
\hline $0-3 \mathrm{mth}$ & $22.8(13 / 57)^{\ddagger}$ & 4.9 & 49.2 & Beta \\
\hline $3-6 \mathrm{mth}$ & $13.6(6 / 44)^{\ddagger}$ & 0.1 & 51.0 & Beta \\
\hline $6-12$ mth & $5.3(2 / 38)^{\ddagger}$ & 0 & 64.7 & Beta \\
\hline $12-18$ mth & $2.8(1 / 36)^{\ddagger}$ & 0.6 & 6.4 & Beta \\
\hline $18-24 \mathrm{mth}$ & $8.67(3 / 35)^{\ddagger}$ & 0 & 60.9 & Beta \\
\hline $24-30 \mathrm{mth}$ & $0(0 / 32)^{\ddagger}$ & 0 & 0 & - \\
\hline \multicolumn{5}{|c|}{ Relative risk of AD, PHF-W:CMF (30) } \\
\hline $0-3$ mth & $0.248([3 / 53] /[13 / 57])^{\S}$ & 0.075 & 0.823 & LogNormal \\
\hline $3-6 \mathrm{mth}$ & $0.440([3 / 50] /[6 / 44])^{\varsigma}$ & 0.117 & 1.656 & LogNormal \\
\hline $6-12 \mathrm{mth}$ & $0.404([1 / 47] /[2 / 38])^{\S}$ & 0.038 & 4.290 & LogNormal \\
\hline $12-18 \mathrm{mth}$ & $0([0 / 46] /[1 / 36])^{\varsigma}$ & 0 & 0 & - \\
\hline $18-24$ mth & $1.268([5 / 46] /[3 / 35])^{\S}$ & 0.325 & 4.952 & LogNormal \\
\hline $24-30 \mathrm{mth}$ & $N A^{\pi}$ & NA & NA & NA \\
\hline \multicolumn{5}{|c|}{ Distribution of patients (\%) } \\
\hline \multicolumn{5}{|l|}{$0-1 \mathrm{yr}^{*}$} \\
\hline Mild AD & 57.5 & 56.6 & 58.5 & Beta \\
\hline Moderate $A D$ & 37.5 & 36.7 & 38.4 & Beta \\
\hline Severe $A D$ & 5.0 & 3.1 & 6.9 & Beta \\
\hline \multicolumn{5}{|l|}{$>1 \mathrm{yr}^{*}$} \\
\hline Mild AD & 81.2 & 79.7 & 82.5 & Beta \\
\hline Moderate $A D$ & 16.0 & 15.1 & 16.9 & Beta \\
\hline Severe $A D$ & 2.9 & 2.4 & 3.4 & Beta \\
\hline \multicolumn{5}{|c|}{ Probability of flares every 12 wk (\%) } \\
\hline \multicolumn{5}{|l|}{$0-1 \mathrm{yr}^{*}$} \\
\hline Mild AD & 11.7 & 7.1 & 17.2 & Beta \\
\hline Moderate $A D$ & 36.7 & 18.9 & 56.6 & Beta \\
\hline Severe $A D$ & 60.0 & 39.8 & 78.6 & Beta \\
\hline \multicolumn{5}{|l|}{$>1 \mathrm{yr}^{*}$} \\
\hline Mild AD & 11.0 & 6.7 & 16.2 & Beta \\
\hline Moderate $A D$ & 35.0 & 18.4 & 53.7 & Beta \\
\hline Severe $A D$ & 63.3 & 38.8 & 84.6 & Beta \\
\hline Mortality $^{\dagger}(\%)$ & 0.0029 & - & - & - \\
\hline
\end{tabular}

*Based on expert opinion. †Mortality rate for children aged $<5$ years, specific to Singapore. ${ }^{(38)} \neq V a l u e s$ in parentheses are no. of events/no. at risk. §Values in parentheses are no. of events/no. at risk in PHF arm divided by no. of events/no. at risk in CMF arm. ๆValue not estimated or used, as probability was 0 in CMF. AD: atopic dermatitis; CMF: standard cow's milk formula; NA: not applicable; PHF-W: partially hydrolysed whey-based formula; PSA: probabilistic sensitivity analysis; uSA: univariate sensitivity analysis

\section{RESULTS}

Administration of PHF-W versus CMF resulted in a nonsignificant $16 \%$ decrease in the proportion of children developing $\mathrm{AD}$ at the end of the 30 -month period $(28.3 \%$ vs. $44.3 \%$; Table V), consistent with the point estimates by Chan et $\mathrm{al}^{(30)}$ (28.3\% vs. $43.9 \%$ ). Over the 30 -month period, the average time between $\mathrm{AD}$ diagnosis and end of the 30-month period (i.e. the time spent with $\mathrm{AD}$ ) decreased by 6.4 months. Additionally, days without AD flare increased by 14.9 days, while QALYs increased by 0.021 QALYs per patient over this period. The overall total discounted cost was lower for PHF-W (SGD 771 [USD 617]) than CMF (SGD 1,309 [USD 1,047]), representing a net cost saving of SGD 538 (USD 430) over the 30-month period. AD-related costs were primarily driven by pharmacological treatments and physician visits (Table V). Net savings associated with the use of PHF-W over CMF started to occur almost immediately, as the net savings after six months were SGD 140 (USD 112).

The ICERs suggested that PHF-W was economically dominant (i.e. had higher effectiveness and lower costs) relative to CMF. Such dominance in terms of costs and QALYs gained was observed in $73 \%$ of the 5,000 multivariate PSA simulations. Furthermore, PHF-W costs were SGD 50,000 (USD 40,000) or less per QALY gained in $87 \%$ of simulations. Finally, multivariate PSA showed that PHF-W reduced the cumulative incidence of AD at Month 30 in $84 \%$ of simulations, increased QALYs in $94 \%$ of simulations and resulted in cost savings in $73 \%$ of simulations. 
Table II. Clinical management and effectiveness inputs.*

\begin{tabular}{|c|c|c|c|c|}
\hline \multirow[t]{3}{*}{ Variable } & \multicolumn{3}{|c|}{$\%$} & \multirow[t]{3}{*}{ PSA distribution } \\
\hline & \multirow[t]{2}{*}{ Base case } & \multicolumn{2}{|c|}{ Value in uSA } & \\
\hline & & Low & High & \\
\hline \multicolumn{5}{|c|}{ Management of AD at 0-1 yr } \\
\hline \multicolumn{5}{|l|}{ Mild AD } \\
\hline Switch formula $^{+}$ & 0 & 0 & 0 & - \\
\hline Combined $^{\ddagger}$ & 1.5 & 1.3 & 1.7 & Beta \\
\hline Medical ${ }^{\S}$ & 98.5 & 98.3 & 98.7 & Beta \\
\hline \multicolumn{5}{|l|}{ Moderate AD } \\
\hline Switch formula ${ }^{\dagger}$ & 0 & 0 & 0 & - \\
\hline Combined $d^{\ddagger}$ & 5.0 & 4.2 & 5.9 & Beta \\
\hline Medical\$ & 95.0 & 94.1 & 95.8 & Beta \\
\hline \multicolumn{5}{|l|}{ Severe AD } \\
\hline Switch formula ${ }^{\dagger}$ & 0 & 0 & 0 & - \\
\hline Combined $^{\ddagger}$ & 20.0 & 18.2 & 21.8 & Beta \\
\hline Medical\$ & 80.0 & 78.2 & 81.8 & Beta \\
\hline \multicolumn{5}{|c|}{ Response rate to combination treatment } \\
\hline \multicolumn{5}{|c|}{ First-line combination treatment } \\
\hline Mild AD & 69.7 & 56.2 & 82.1 & Beta \\
\hline Moderate $A D$ & 69.7 & 56.2 & 82.1 & Beta \\
\hline Severe $A D$ & 69.7 & 56.2 & 82.1 & Beta \\
\hline \multicolumn{5}{|c|}{ Second-line combination treatment } \\
\hline Mild AD & 69.7 & 56.2 & 82.1 & Beta \\
\hline Moderate $A D$ & 69.7 & 56.2 & 82.1 & Beta \\
\hline Severe $A D$ & 69.7 & 56.2 & 82.1 & Beta \\
\hline \multicolumn{5}{|c|}{ Third-line combination treatment } \\
\hline Mild AD & 69.7 & 56.2 & 82.1 & Beta \\
\hline Moderate $A D$ & 69.7 & 56.2 & 82.1 & Beta \\
\hline Severe $A D$ & 69.7 & 56.2 & 82.1 & Beta \\
\hline \multicolumn{5}{|c|}{ Response rate to pharmacotherapy } \\
\hline \multicolumn{5}{|c|}{ First-line pharmacotherapy } \\
\hline \multicolumn{5}{|l|}{ Response $<1$ yr } \\
\hline$\underline{\text { Mild AD }}$ & 84.7 & 56.8 & 98.9 & Beta \\
\hline Moderate AD & 66.7 & 61.0 & 72.1 & Beta \\
\hline$\underline{\text { Severe AD }}$ & 55.0 & 43.1 & 66.6 & Beta \\
\hline \multicolumn{5}{|l|}{ Response $>1 \mathrm{yr}$} \\
\hline$\underline{\text { Mild AD }}$ & 83.0 & 51.1 & 99.0 & Beta \\
\hline Moderate AD & 63.3 & 59.3 & 67.3 & Beta \\
\hline$\underline{\text { Severe AD }}$ & 48.3 & 22.8 & 74.4 & Beta \\
\hline \multicolumn{5}{|c|}{ Second-line pharmacotherapy } \\
\hline Mild AD & 73.0 & 29.8 & 98.4 & Beta \\
\hline Moderate $A D$ & 73.0 & 29.8 & 98.4 & Beta \\
\hline Severe $A D$ & 73.0 & 29.8 & 98.4 & Beta \\
\hline \multicolumn{5}{|c|}{ Third-line pharmacotherapy } \\
\hline Mild AD & 79.9 & 44.7 & 98.7 & Beta \\
\hline Moderate $A D$ & 79.9 & 44.7 & 98.7 & Beta \\
\hline Severe $A D$ & 79.9 & 44.7 & 98.7 & Beta \\
\hline
\end{tabular}

*Based on expert opinion. +Switch formula involved the switching of infant formula only. ₹Combined involved a switching of infant formula and addition of first-line pharmacotherapy. §Medical involved the addition of first-line pharmacotherapy only. AD: atopic dermatitis; PSA: probabilistic sensitivity analysis; uSA: univariate sensitivity analysis 
Table III. Quantity of resources used per patient to treat AD by severity at presentation.*

\begin{tabular}{|c|c|c|c|c|c|c|}
\hline \multirow[t]{2}{*}{ Resource } & \multicolumn{3}{|c|}{ Upon initial development of AD } & \multicolumn{3}{|c|}{ During follow-up of $A D$ treatment ${ }^{\dagger}$} \\
\hline & Mild & Moderate & Severe & Mild & Moderate & Severe \\
\hline \multicolumn{7}{|l|}{ No. of physician visits per child } \\
\hline Generalist/paediatrician & 0.50 & 1.00 & 0.83 & 0.20 & 1.00 & 0.70 \\
\hline Specialist & 0.36 & 0.94 & 1.82 & 0.38 & 1.45 & 3.17 \\
\hline \multicolumn{7}{|l|}{ No. of hospitalisations per child } \\
\hline Age $<12 \mathrm{mth}$ & 0 & 0 & 0.17 & - & - & - \\
\hline Age $>12 \mathrm{mth}$ & 0 & 0 & 0.24 & - & - & - \\
\hline \multicolumn{7}{|l|}{ No. of diagnostic tests per child } \\
\hline Skin prick test & 0.02 & 0.37 & 0.50 & - & - & - \\
\hline Specific lgE test & 0 & 0.07 & 0.11 & - & - & - \\
\hline Food elimination diet & 0 & 0.05 & 0.18 & - & - & - \\
\hline Oral food challenge test & 0 & 0 & 0.02 & - & - & - \\
\hline Bacterial culture & 0 & 0.10 & 0.50 & - & - & - \\
\hline \multicolumn{7}{|l|}{ Pharmacotherapy units per child } \\
\hline Emollient cream (100 g/unit) & 1.26 & 4.17 & 7.27 & 1.13 & 2.22 & 4.28 \\
\hline Hydrocortisone (15 g/unit) & 0.70 & 1.10 & 2.55 & 0.32 & 0.55 & 1.21 \\
\hline Medium-strength topical corticosteroid ( $15 \mathrm{~g} / \mathrm{unit})$ & 0.17 & 1.03 & 2.73 & 0.13 & 0.55 & 1.33 \\
\hline Chlorhexidine wash (200 mL/unit) & 0.13 & 0.33 & 1.20 & 0.07 & 0.27 & 0.60 \\
\hline Tacrolimus (10 g/unit) & 0 & 0.10 & 0.33 & 0 & 0.07 & 0.18 \\
\hline Oral prednisolone (10 tablets) & - & - & 0.17 & - & - & 0.03 \\
\hline \multicolumn{7}{|l|}{ Other cost } \\
\hline Time lost attending AD patient (hr) & 4.00 & 4.00 & 4.00 & - & - & - \\
\hline Time lost per physician visit (hr) & 2.00 & 2.00 & 2.00 & 2.00 & 2.00 & 2.00 \\
\hline No. of trips per physician visit & 1.00 & 1.00 & 1.00 & 1.00 & 1.00 & 1.00 \\
\hline
\end{tabular}

*Based on expert opinion. All parameters were varied by $\pm 25 \%$ in univariate and multivariate sensitivity analyses (via uniform distributions). + In cases of non-response and/or flares. AD: atopic dermatitis; IgE: immunoglobulin $\mathrm{E}$

Results from uSA indicated that initial formula costs and AD relative risk had the greatest impact on the findings. When the cost of PHF-W was increased by $25 \%$, or the cost of CMF decreased by $25 \%$, PHF-W use resulted in a net cost relative to CMF (up to +SGD 133 [USD 106] in one scenario). In contrast, PHF-W had savings of SGD 93 (USD 74) even when the most conservative assumptions were used for AD relative risk during Months 6-12 (i.e. when PHF-W was assumed to increase AD risk 4.290 times vs. CMF; Table I). In all other scenarios, results were even more favourable for PHF-W.

Finally, costs per incident AD case were estimated. The average total cost of developing AD within the first 30 months of life was SGD 2,554 (USD 2,043) and the annual undiscounted cost was SGD 1,516 (USD 1,213) - including SGD 1,258 (USD 1,006) in direct costs - regardless of initial formula fed. The annual number of physician visits per AD case was estimated at 3.51 , with $1.15,6.46$ and 14.53 visits for mild, moderate and severe cases, respectively.

\section{DISCUSSION}

Exclusive breastfeeding is the absolute gold standard for feeding infants. ${ }^{(14,47)}$ However, not all infants are able to receive exclusive breastfeeding in practice. When this is the case, formula feeding may be the second choice. ${ }^{(47)}$ In these circumstances, a shortterm early nutritional intervention with PHF-W instead of CMF for infants with a family history of atopy is suggested to be more effective and cost-saving. Specifically, our study showed that in the base-case analysis, this strategy (applied to children exclusively fed with formula) resulted in a nonsignificant $16 \%$ reduction in the proportion of children developing AD (PHF-W: $28.3 \%$ vs. CMF: $44.3 \%$ ) at the end of the 30-month period, consistent with Chan et al's findings. ${ }^{(30)}$ Exclusive feeding with PHF-W was also projected to decrease the number of days spent with an AD flare, from 27.2 days to 12.3 days (difference: 14.9 days), and increase discounted QALYs by 0.021 over the entire 30-month follow-up period. In addition, the use of PHF-W was projected to result in a net discounted savings of SGD 538 (USD 430) per infant over the same time period, after including the additional cost of PHF-W over CMF. Savings were driven primarily by reductions in costs associated with pharmacotherapy, physician visits and indirect costs.

Our study has a unique strength, as it relies upon $\mathrm{AD}$ incidence data from a Singapore trial for both analysis arms. While the selection of Singapore trial data for an economic analysis relevant to Singapore seems obvious, other data sources could also have been used. Specifically, one alternative could have been to rely upon the GINI trial, as, given its sample size and duration of follow-up, it was arguably the best available evidence on the clinical benefits of the nutritional intervention assessed herein. In fact, the results presented here are consistent with results from a comparable analysis applying 
Table IV. Summary of cost and quality of life inputs.

\begin{tabular}{|c|c|c|c|}
\hline \multirow[t]{2}{*}{ Variable } & \multirow[t]{2}{*}{ Mean value } & \multicolumn{2}{|c|}{ Value in uSA } \\
\hline & & Low & High \\
\hline \multicolumn{4}{|l|}{ Formula (cost per unit)* } \\
\hline PHF-W & SGD 53.20/800 g & SGD 39.90 & SGD 66.50 \\
\hline CMF & SGD 55.45/900 g & SGD 41.59 & SGD 69.31 \\
\hline Soy & SGD 55.45/900 g & SGD 41.59 & SGD 69.31 \\
\hline EHF & SGD $42.00 / 400 \mathrm{~g}$ & SGD 31.50 & SGD 52.50 \\
\hline \multicolumn{4}{|l|}{ Pharmacotherapy (cost per unit) } \\
\hline Emollient cream & SGD 22.50 & SGD 16.88 & SGD 28.13 \\
\hline Hydrocortisone & SGD 5.00 & SGD 3.75 & SGD 6.25 \\
\hline Medium-strength topical corticosteroid & SGD 25.00 & SGD 18.75 & SGD 31.25 \\
\hline Chlorhexidine wash & SGD 9.00 & SGD 6.75 & SGD 11.25 \\
\hline Tacrolimus & SGD 75.00 & SGD 56.25 & SGD 93.75 \\
\hline Oral prednisolone & SGD 1.00 & SGD 0.75 & SGD 1.25 \\
\hline \multicolumn{4}{|l|}{ Physician visits (cost per unit) } \\
\hline Generalist/paediatrician & SGD 35.00 & SGD 26.25 & SGD 43.75 \\
\hline Specialist (allergist/dermatologist) & SGD 150.00 & SGD 112.50 & SGD 187.50 \\
\hline \multicolumn{4}{|l|}{ Hospitalisations (cost per unit) ${ }^{\dagger}$} \\
\hline Severe AD & SGD 8,934.00 & SGD 6,700.50 & SGD $11,167.50$ \\
\hline \multicolumn{4}{|l|}{ Laboratory tests (cost per unit) $^{\ddagger}$} \\
\hline Mild AD & SGD 4.73 & SGD 3.55 & SGD 5.92 \\
\hline Moderate AD & SGD 7.67 & SGD 5.75 & SGD 9.59 \\
\hline Severe AD & SGD 15.43 & SGD 11.57 & SGD 19.29 \\
\hline \multicolumn{4}{|l|}{ Other costs (per unit) } \\
\hline Cost of $1 \mathrm{hr}$ of time loss & SGD 21.16 & SGD 15.85 & SGD 26.42 \\
\hline Travel cost per visit & SGD 16.13 & SGD 12.10 & SGD 20.16 \\
\hline \multicolumn{4}{|l|}{ Utilities $^{(44,45)}$} \\
\hline Mild AD & 0.8625 & 0.6691 & 0.9771 \\
\hline Moderate AD & 0.6900 & 0.5674 & 0.8004 \\
\hline Severe AD & 0.5900 & 0.3028 & 0.8463 \\
\hline Mild ADCS & 0.9800 & 0.8577 & 1.0000 \\
\hline Moderate ADCS & 0.9800 & 0.8828 & 1.0000 \\
\hline Severe ADCS & 0.9800 & 0.9323 & 0.9992 \\
\hline
\end{tabular}

Costs in 2013 SGD (SGD $1.00=$ USD 0.80). All distributions for costs in probabilistic sensitivity analysis (PSA) were uniform. All distributions for utilities in PSA were beta. *Recommended quantities from the package inserts were used to determine quantity of formula for daily consumption. The daily intake of the infant formula was calculated according to Iskedjian et al. ${ }^{(31)}+$ Estimated based on general room rates derived from four hospitals in Singapore. \#Estimated based on average hospital laboratory test rates, as reported by physicians in Singapore. AD: atopic dermatitis; ADCS: AD-controlled state; CMF: standard cow's milk formula; EHF: extensively hydrolysed formula; PHF-W: partially hydrolysed whey-based formula; uSA: univariate sensitivity analyses

the six-year data from the GINI study to the Singaporean setting. ${ }^{(48)}$ Bhanegaonkar et al have analysed that the delay and/or prevention of $\mathrm{AD}$ using PHF-W resulted in a 16-day increase in the number of days without AD flare and a QALY gain of 0.022 (95\% confidence interval $[\mathrm{Cl}]$ 0.005-0.075). ${ }^{(48)}$ In their study, net costs with PHF-W were SGD 739 less than with CMF (PHF-W: SGD 1,316 vs. CMF: SGD 2,055; 95\% Cl: -SGD 1,341 to -SGD 142). These findings and our results using Singapore trial data are consistent with similar GINI-based analyses from Western countries, ${ }^{(31-34)}$ the Philippines ${ }^{(36)}$ and Malaysia. ${ }^{(35)}$ This consistency was to be expected since our study adopted many of the methods used in previous work. ${ }^{(31-34)}$

An alternative data source for efficacy of the intervention was one of several meta-analyses. ${ }^{(21,27-29)}$ However, there is some disagreement among meta-analyses conducted at varying times by different researchers regarding the effect of hydrolysed formula on AD risk. Three such analyses ${ }^{(21,27,28)}$ concluded several years ago that hydrolysed formulas are recommended in the first 4-6 months of life for the primary prevention of allergic diseases in highrisk infants who are unable to be completely breastfed. A more recent meta-analysis by Boyle et $\mathrm{al}^{(29)}$ came to a very different conclusion, adopting a more critical assessment of the published literature (notably concerning publication bias, among others). It indicated that the current guidelines recommending hydrolysates to prevent allergic disease in high-risk infants are not supported. The authors reported that there was no consistent evidence of hydrolysed formulas reducing the risk of $\mathrm{AD}$ in infants at high risk (odds ratio for eczema at age 0-4 months was $0.84[95 \% \mathrm{Cl}$ 0.67-1.07] for PHF when compared to CMF). ${ }^{(29)}$ 
Table V. Base-case results for an average healthy formula-fed infant at high risk of developing AD.

\begin{tabular}{|c|c|c|c|}
\hline Result & PHF-W & CMF & Difference \\
\hline \multicolumn{4}{|l|}{ Undiscounted result } \\
\hline Proportion who develop AD & 0.283 & 0.443 & -0.161 \\
\hline Days with AD flare & 12.3 & 27.2 & -14.9 \\
\hline Months of life after AD diagnosis & 4.5 & 10.9 & -6.4 \\
\hline QALY & 2.485 & 2.463 & 0.021 \\
\hline \multicolumn{4}{|l|}{ Cost (SGD [USD]) } \\
\hline Formula for AD risk reduction* & $197(158)$ & - & $197(158)$ \\
\hline Formula treatment & $1(1)$ & $3(2)$ & $-2(-2)$ \\
\hline Physician visits & $145(116)$ & $324(259)$ & $-180(-144)$ \\
\hline Pharmacotherapy & $319(255)$ & $760(608)$ & $-441(-353)$ \\
\hline Diagnostic testing & $2(2)$ & $3(2)$ & $-1(-1)$ \\
\hline Hospitalisation & $19(15)$ & $33(26)$ & $-13(-10)$ \\
\hline Indirect cost & $105(84)$ & $216(173)$ & $-112(-90)$ \\
\hline Total cost & $788(630)$ & $1,339(1,071)$ & $-551(-441)$ \\
\hline \multicolumn{4}{|l|}{ Discounted result } \\
\hline Proportion who develop AD & 0.277 & 0.441 & -0.165 \\
\hline Days with AD flare & 12.0 & 26.7 & -14.7 \\
\hline QALY & 2.425 & 2.404 & 0.021 \\
\hline Total cost (SGD [USD]) & $771(617)$ & $1,309(1,047)$ & $-538(-430)$ \\
\hline \multicolumn{4}{|l|}{ Discounted ICER } \\
\hline Cost per AD case avoided & - & - & Dominant $^{\dagger}$ \\
\hline Cost per AD-free day gained & - & - & Dominant $^{\dagger}$ \\
\hline Cost per QALY gained & - & - & Dominant $^{\dagger}$ \\
\hline
\end{tabular}

Costs in 2013 SGD (SGD $1.00=$ USD 0.80). All conversions were rounded to the nearest integer and hence difference may not correspond to subtracted values. *Formula costs for reducing AD risk or treating AD were the excess costs beyond CMF feeding costs. $+P H F-W$ was dominant when effectiveness was higher and costs lower than CMF. AD: atopic dermatitis; CMF: standard cow's milk formula; ICER: incremental cost-effectiveness ratio; PHF-W: partially hydrolysed whey-based formula; QALY: quality-adjusted life year

However, this meta-analysis is somewhat controversial and has been criticised on multiple methodological grounds. ${ }^{(47,49)}$ In particular, Boyle et al ${ }^{(29)}$ used very broad study selection criteria, as studies of any type of hydrolysed formula were included and compared to any other type of infant feeding, regardless of methodological quality. ${ }^{(47,49)}$ A particular concern is that very different protein hydrolysates should not be pooled together based on an assumed similar degree of hydrolysis. ${ }^{(47,49)}$ Indeed, different biological effects of different hydrolysates are based on molecular mass distribution, different peptide characteristics and sequence profiles, which are quite consistent among different batches of the same product. ${ }^{(49)}$ These differences may be, in part, a reason why the European Food Safety Authority never accepted claims for preventive efficacy for hydrolysed formulas to be taken as a group, but rather, supported the separate evaluation of each particular product. ${ }^{(49)}$ As noted by Vandenplas, ${ }^{(47)}$ some of the hydrolysates studied by Boyle et al $^{(29)}$ were never commercialised.

Thus, in light of the ongoing intense controversy related to the various meta-analyses, we opted to use what we considered to be the best available evidence to date on the effect of PHF-W on the risk of $\mathrm{AD}$ in Singapore, particularly because this evidence was also consistent with the GINI data and leads to comparable economic results. Naturally, if the underlying assumption regarding the efficacy of PHF-W versus CMF adopted in our study were to be rejected on the basis of new evidence confirming the findings of the meta-analysis by Boyle et al, ${ }^{(29)}$ our conclusions regarding the cost-effectiveness of PHF-W would have to be revisited.

One of the limitations of our study, and an area worthy of future research, was the lack of detailed published Singapore data on AD treatment patterns and effectiveness. Therefore, assumptions were adopted based on expert opinion. This challenge and the need to rely on expert opinion are important and known limitations that are not unique to our study. Costeffectiveness analyses in Western countries ${ }^{(31,33,34)}$ have also relied upon similar data collection methods and evidence standards adopted herein. In part, the reliance on expert opinion was dictated by the clinical diagnosis of $A D$ and its subjective assessment of severity. AD diagnosis and management are not routinely recorded administratively for reimbursement purposes. Hence, many AD treatments require out-of-pocket expenditure that has to be borne by families. These may be under-recorded and are difficult to estimate.

Our study may have been conservative in that AD effects beyond the initial 30 months were excluded despite evidence that AD often continues into adulthood. ${ }^{(9)}$ Additionally, other allergic manifestations, which may potentially be reduced with PHF-W use, were ignored. The impact of AD on parental productivity 
was only partially considered because reliable data was lacking. Finally, the impact of AD on parental QOL was ignored entirely, despite the negative impact of $\mathrm{AD}$ on the physical and mental health of mothers. ${ }^{(12)}$

Despite the above limitations, the validity of our study can partially be assessed by comparing the estimated AD costs to similar estimates from other countries. In our present analysis, the average annual undiscounted total cost for an incident AD case was estimated at SGD 1,516 (USD 1,213), including SGD 1,258 (USD 1,006) in direct costs. These figures were lower when compared to Australia, as reported by Su et al ${ }^{(10)}$ (total cost: USD 6,187, direct cost: USD 4,842), and South Korea, by Kang et $\mathrm{al}^{(50)}$ (total cost: USD 3,522, direct cost: USD 1,253), with all costs inflated to 2012-2013 levels and converted to USD. This was in part due to differences in treatment setting (dermatology clinic in Australia and allergy clinic in Korea) that may have resulted in having more patients with moderate or severe AD. In contrast, the cost $\mathrm{Su}$ et $\mathrm{al}^{(33)}$ reported in Australia more recently was USD 1,926, including only USD 257 in direct costs (all excluding formula costs). Finally, using a variety of sources, including an international survey of patients with $\mathrm{AD}$ and expert opinion, Tang et $\mathrm{al}^{(51)}$ estimated that annual treatment costs for $\mathrm{AD}$ patients aged seven years in high-income Asian countries (including Singapore) had a range of USD 1,293-2,079 depending on the emollient used - consistent with (if not higher than) the estimates presented in our study. Based on the current analysis, the annual number of visits necessary to manage AD (overall: 3.51 visits; mild cases: 1.15 visits; moderate cases: 6.46 visits; severe cases: 14.53 visits) was conservative compared to values for Australia in a dermatology clinic setting with more severe $\mathrm{AD}$, as reported by $\mathrm{Su}$ et $\mathrm{al}^{(10)}$ (overall: 12.9 visits; mild cases: 7.0 visits; moderate cases: 13.0 visits; severe cases: 23.3 visits), and the results of a cost-effectiveness analysis of PHF-W versus CMF conducted in Germany (5.4 annual visits). ${ }^{(34)}$

We further tested the conclusions of our study via multivariate PSA, in which the model results were calculated 5,000 times via Monte Carlo simulation techniques, using a different value for each input parameter from appropriate theoretical or empirical distributions. This was done to assess the overall uncertainty associated with the model inputs, including expert opinion and the trial reported by Chan et al. ${ }^{(30)}$ The authors had concluded that the cumulative eczema incidence in the PHF-W group compared to the CMF group was significantly lower at three, six, 12, 18 and 24 months, and lower (PHF-W: 28.3\%, CMF: 43.9\%) at Month 30 (albeit not at the very end of the trial), suggesting that the use of PHF-W did not completely prevent but had possibly delayed

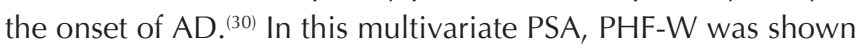
to dominate $\mathrm{CMF}$ in $73 \%$ of the simulations (i.e. PHF-W resulted in QALY gained and lower cost compared to CMF). Furthermore, the PHF-W cost of SGD 50,000 (USD 40,000) or less per QALY in $87 \%$ of simulations suggested that it was probably, but not certainly, a cost-effective intervention. In other words, while the results suggested that PHF-W is cost-effective in $87 \%$ of simulations, the possibility remains that PHF-W was not costeffective when compared to CMF (i.e. in 13\% of simulations,
PHF-W cost was over SGD 50,000 per QALY gained). The lack of certainty regarding the economic results was due, in part, to uncertainty associated with the clinical effects (CMF resulted in fewer AD cases at Month 30 in 16\% of simulations and in QALY gained over the entire 30 -month follow-up in $6 \%$ of simulations) as well as economic uncertainty (CMF resulted in cost savings in $27 \%$ of simulations). Taken together, these PSA results suggest that, if one is willing to accept the results from the Chan et al trial $^{(30)}$ and the assumptions used in the model, and further, if one is willing to pay up to SGD 50,000 per QALY gained in Singapore, then there is a $87 \%$ probability that the use of PHF-W is cost-effective.

Given the results of our study and considering the controversy over the evidence on this topic, healthcare practitioners in Singapore should look beyond those at high risk due to having at least one first-degree family member with atopy. Other noneconomic factors that may impact the risk of allergic conditions, such as preterm birth and high infant weight gain, ${ }^{(52)}$ should be taken into consideration when determining, on an individual basis, the most appropriate choice of infant formula for use with high-risk infants who are not exclusively breastfed.

In conclusion, this study provides heretofore unavailable information on the economic impact of $A D$ delay and/or prevention via an early, short-term nutritional infant formula for high-risk infants in Singapore. In healthy Singapore infants with a family history of allergy who are not exclusively breastfed, the strategy of using PHF-W as a short-term initial infant formula instead of CMF is expected, on average, to reduce AD burden, improve QOL and result in net cost savings.

\section{ACKNOWLEDGEMENTS}

This research was sponsored by Nestlé Nutrition Institute. Abhijeet J Bhanegaonkar and Xiang Ji were, and Erica G Horodniceanu and Marc F Botteman are, employee(s) and/or owner of Pharmerit International, which received partial research funding from Nestlé Nutrition Institute, Vevey, Switzerland, to conduct this study. Patrick Detzel is an employee of Nestlé Research Center, Lausanne, Switzerland, which funded this study. Bee Wah Lee received honoraria for lectures sponsored by Nestlé. The Nestlé Research Center, Lausanne, is part of Nestlé, which manufactures and commercialises Nestle NAN HA®, one of the products evaluated in this study. Pharmerit International retained independent control of the methodology and presentation of the results of this study. The authors would like to thank Beth Lesher and Catherine A O'Connor for editorial assistance on this manuscript.

\section{REFERENCES}

1. Eichenfield LF, Tom WL, Chamlin SL, et al. Guidelines of care for the management of atopic dermatitis: section 1. Diagnosis and assessment of atopic dermatitis. J Am Acad Dermatol 2014; 70:338-51.

2. Tay YK, Kong KH, Khoo L, Goh CL, Giam YC. The prevalence and descriptive epidemiology of atopic dermatitis in Singapore school children. Br J Dermatol 2002; 146:101-6.

3. Odhiambo JA, Williams HC, Clayton TO, Robertson CF, Asher MI; ISAAC Phase Three Study Group. Global variations in prevalence of eczema symptoms in children from ISAAC Phase Three. J Allergy Clin Immunol 2009; 124:1251-8.e23. 
4. Tan TN, Shek LP, Goh DY, Chew FT, Lee BW. Prevalence of asthma and comorbid allergy symptoms in Singaporean preschoolers. Asian Pac J Allergy Immunol 2006; 24:175-82.

5. Wang XS, Tan TN, Shek LP, et al. The prevalence of asthma and allergies in Singapore; data from two ISAAC surveys seven years apart. Arch Dis Child 2004; 89:423-6.

6. Van Bever HP, Llanora G. Features of childhood atopic dermatitis. Asian Pac J Allergy Immunol 2011; 29:15-24.

7. Lee JT, Lam ZC, Lee WT, et al. Familial risk of allergic rhinitis and atopic dermatitis among Chinese families in Singapore. Ann Acad Med Singapore 2004; 33:71-4.

8. Van Bever HP, Samuel ST, Lee BW. Halting the allergic march. World Allergy Organ J 2008; 1:57-62

9. Margolis JS, Abuabara K, Bilker W, Hoffstad O, Margolis DJ. Persistence of mild to moderate atopic dermatitis. JAMA Dermatol 2014; 150:593-600.

10. Su JC, Kemp AS, Varigos GA, Nolan TM. Atopic eczema: Its impact on the family and financial cost. Arch Dis Child 1997; 76:159-62.

11. Lewis-Jones S. Quality of life and childhood atopic dermatitis: the misery of living with childhood eczema. Int J Clin Pract 2006; 60:984-92.

12. Ho RC, Giam YC, Ng TP, et al. The influence of childhood atopic dermatitis on health of mothers, and its impact on Asian families. Pediatr Allergy Immunol 2010; 21:501-7.

13. Anuntaseree W, Sangsupawanich P, Osmond C, et al. Sleep quality in infants with atopic dermatitis: a community-based, birth cohort study. Asian Pac Allergy Immunol 2012; 30:26-31.

14. World Health Organization. Infant and young child nutrition. Global strategy on infant and young child feeding. Report by the Secretariat. Fifty-fifth World Health Assembly. 2002 April 16. Report No.: A55/15. Provisional agenda item 13.10.

15. Victora CG, Bahl R, Barros AJ, et al; Lancet Breastfeeding Series Group. Breastfeeding in the 21st century: epidemiology, mechanisms, and lifelong effect. Lancet 2016; 387:475-90.

16. Eidelman Al, Schanler RJ, Johnston $\mathrm{M}$, et al. Breastfeeding and the use of human milk. Pediatrics 2012; 129:e827-e41.

17. Matheson MC, Allen KJ, Tang ML. Understanding the evidence for and agains the role of breastfeeding in allergy prevention. Clin Exp Allergy 2012; 42:827-51.

18. Kneepkens CM, Brand PL. Clinical practice: breastfeeding and the prevention of allergy. Eur J Pediatr 2010; 169:911-7.

19. Suh J, Lee H, Lee JH, et al. Natural course of cow's milk allergy in children with atopic dermatitis. J Korean Med Sci 2011; 26:1152-8.

20. Novembre E, Vierucci A. Milk allergy/intolerance and atopic dermatitis in infancy and childhood. Allergy 2001; 56 Suppl 67:105-8

21. Alexander DD, Cabana MD. Partially hydrolyzed $100 \%$ whey protein infan formula and reduced risk of atopic dermatitis: a meta-analysis. J Pediat Gastroenterol Nutr 2010; 50:422-30.

22. Greer FR, Sicherer SH, Burks AW; American Academy of Pediatrics Committee on Nutrition; American Academy of Pediatrics Section on Allergy and Immunology. Effects of early nutritional interventions on the development of atopic disease in infants and children: the role of maternal dietary restriction, breastfeeding, timing of introduction of complementary foods, and hydrolyzed formulas. Pediatrics 2008; 121:183-91.

23. Host A, Koletzko B, Dreborg S, et al. Dietary products used in infants for treatment and prevention of food allergy. Joint statement of the European Society for Paediatric Allergology and Clinical Immunology (ESPACI) Committee on Hypoallergenic Formulas and the European Society for Paediatric Gastroenterology, Hepatology and Nutrition (ESPGHAN) Committee on Nutrition. Arch Dis Child 1999; 81:80-4.

24. von Berg A, Filipiak-Pittroff B, Krämer U, et al; GINIplus study group. Preventive effect of hydrolyzed infant formulas persists until age 6 years: long-term results from the German Infant Nutritional Intervention Study (GINI). J Allergy Clin Immunol 2008; 121:1442-7.

25. Alexander DD, Schmitt DF, Tran NL, Barraj LM, Cushing CA. Partially hydrolyzed $100 \%$ whey protein infant formula and atopic dermatitis risk reduction: a systematic review of the literature. Nutr Rev 2010; 68:232-45.

26. von Berg A, Filipiak-Pittroff B, Kramer U, et al; GINIplus study group. Allergies in high-risk schoolchildren after early intervention with cow's milk protein hydrolysates: 10-year results from the German Infant Nutritional Intervention (GINI) study. J Allergy Clin Immunol 2013; 131:1565-73.

27. Szajewska $\mathrm{H}$, Horvath A. Meta-analysis of the evidence for a partially hydrolyzed $100 \%$ whey formula for the prevention of allergic diseases. Curr Med Res Opin 2010; 26:423-37.

28. Osborn DA, Sinn J. Formulas containing hydrolysed protein for prevention of allergy and food intolerance in infants. Cochrane Database Syst Rev 2003 (4):CD003664.

29. Boyle RJ, lerodiakonou D, Khan T, et al. Hydrolysed formula and risk of allergic or autoimmune disease: systematic review and meta-analysis. BMJ 2016; 352:i974.

30. Chan YH, Shek LP, Aw M, Quak SH, Lee BW. Use of hypoallergenic formula in the prevention of atopic disease among Asian children. J Paediatr Child Health $2002 ; 38: 84-8$

31. Iskedjian M, Dupont C, Spieldenner J, et al. Economic evaluation of a $100 \%$ whey-based, partially hydrolysed formula in the prevention of atopic dermatitis among French children. Curr Med Res Opin 2010; 26:2607-26.

32. Iskedjian M, Belli D, Farah B, Navarro V, Detzel P. Economic evaluation of a $100 \%$ whey-based partially hydrolyzed infant formula in the prevention of atopic dermatitis among Swiss children. J Med Econ 2012; 15:378-93.

33. Su J, Prescott S, Sinn J, et al. Cost-effectiveness of partially-hydrolyzed formula for prevention of atopic dermatitis in Australia. J Med Econ 2012; 15:1064-77.

34. Mertens J, Stock S, Lungen M, et al. Is prevention of atopic eczema with hydrolyzed formulas cost-effective? A health economic evaluation from Germany. Pediatr Allergy Immunol 2012; 23:597-604

35. Bhanegaonkar AJ, Horodniceanu EG, Abdul Latiff AH, et al. Economic value of atopic dermatitis prevention via infant formula use in high-risk Malaysian infants. Asia Pac Allergy 2015; 5:84-97.

36. Bhanegaonkar AJ, Horodniceanu EG, Gonzalez RRH, et al. Cost-effectiveness of partially hydrolyzed whey protein formula in the primary prevention of atopic dermatitis in at-risk urban Filipino infants. Value Health Reg Issues 2014; 3:124-35.

37. Sonnenberg FA, Beck JR. Markov models in medical decision making: a practical guide. Med Decis Making 1993; 13:322-38.

38. World Bank data. Singapore mortality rate, under 5. Available at: http:// www.google.com/publicdata/explore?ds=d5bncppjof8f9_\&ctype=I\&met_ $\mathrm{y}=$ sh_dyn_mort\&hl=en\&dl=en\#!ctype $=\mid$ \&strail=false\&bcs $=\mathrm{d} \&$ nselm $=\mathrm{h} \& \mathrm{met}$ $y=s h \_d y n \_m o r t \& s c a l e_{-} y=l i n \& i n d \_y=f a l s e \& r d i m=$ country\&idim =country: SGP\&ifdim=country\&hl=en_US\&dl=en\&ind=false. Accessed May 12, 2014.

39. Euromonitor International. Packaged food: Euromonitor from trade sources/ national statistics for Singapore, February 2013. Available at: http://www. euromonitor.com/packaged-food. Accessed November 26, 2013.

40. Ministry of Health Singapore. Available at: http://www.moh.gov.sg/content/ moh_web/home.html. Accessed August 1, 2013.

41. Salary Explorer. Salary survey in Singapore. Available at: http://www.salaryexplorer. com/salary-survey.php?loc=196\&loctype=1. Accessed March 30, 2014.

42. Manpower Research and Statistics Department, Ministry of Manpower, Republic of Singapore. Labour force in Singapore, 2013. ISSN 0129-6965. Available at: http://stats.mom.gov.sg/Pages/Labour-Force-In-Singapore-2013.aspx. Accessed March 30, 2014.

43. Price of Travel. World taxi prices: What a 3-kilometer ride costs in 72 big cities. Available at: http://www.priceoftravel.com/555/world-taxi-prices-what-a-3kilometer-ride-costs-in-72-big-cities/. Accessed November 26, 2013.

44. Pitt M, Garside R, Stein K. A cost-utility analysis of pimecrolimus vs. Topical corticosteroids and emollients for the treatment of mild and moderate atopic eczema. Br J Dermatol 2006; 154:1137-46.

45. Stevens KJ, Brazier JE, McKenna SP, Doward LC, Cork MJ. The development of a preference-based measure of health in children with atopic dermatitis. $\mathrm{Br}$ J Dermatol 2005; 153:372-7.

46. Siegel JE, Torrance GW, Russell LB, et al. Guidelines for pharmacoeconomic studies. Recommendations from the panel on cost effectiveness in health and medicine. Panel on cost effectiveness in health and medicine. Pharmacoeconomics 1997; 11:159-68.

47. Vandenplas Y. Study finds little impact of hydrolysed formula on risk of allergic disease, but study methods may limit conclusions and generalisability. Evid Based Med 2016; 21:157.

48. Bhanegaonkar A SL, Lee BW, Van Bever HP, Horodniceanu EG, Ji X, et al. Modeling the cost-effectiveness of $100 \%$ whey-based partially hydrolyzed versus cow's milk infant formula in the prevention of atopic dermatitis in Singapore. Value Health 2014; 17:A779.

49. Koletzko S, Filipiak-Pittroff B, Heinrich J, et al. Letter to the editor on: Hydrolysed formula and risk of allergic or autoimmune disease: systematic review and meta-analysis. 07 May 2016. Available at: http://www.bmj.com/content/352/ bmj.1974/rapid-responses. Accessed January 24, 2017.

50. Kang KH, Kim K-W, Kim DH. Utilization pattern and cost of medical treatment and complementary alternative therapy in children with atopic dermatitis. Pediatr Allergy Respir Dis 2012; 22:27-36.

51. Tang MB, Leong KF, Ou LS, et al. Cost-effectiveness study of pediatric atopic dermatitis in Asia: atopiclair vs. regular emollient (AD-ATOP). J Drugs Dermatol 2015; 14:169-75.

52. Sonnenschein-van der Voort AM, Arends LR, de Jongste JC, et al. Preterm birth, infant weight gain, and childhood asthma risk: a meta-analysis of 147,000 European children. J Allergy Clin Immunol 2014; 133:1317-29. 